\title{
Reduction of Optimum Bitumen Content in Polyethylene Modified Bituminous Mixes
}

\author{
Shahreena Melati Rhasbudin Shah, Nor Izzah Zainuddin, Yee Hooi Min, \\ Nur Ain Izzati Nasaruddin, Tey Li Sian
}

Faculty of Civil Engineering, Universiti Teknologi MARA Pulau, Pinang, Malaysia

Email address:

shahr129@ppinang.uitm.edu.my (S. M. R. Shah), norizzah@ppinang.uitm.edu.my (N. I. Zainuddin), minyh@ppinang.uitm.edu.my (Y. H. Min)

\section{To cite this article:}

Shahreena Melati Rhasbudin Shah, Nor Izzah Zainuddin, Yee Hooi Min, Nur Ain Izzati Nasaruddin, Tey Li Sian. Reduction of Optimum Bitumen Content in Polyethylene Modified Bituminous Mixes. American Journal of Civil Engineering. Vol. 6, No. 3, 2018 , pp. $93-98$. doi: 10.11648/j.ajce.20180603.12

Received: April 24, 2018; Accepted: June 21, 2018; Published: June 26, 2018

\begin{abstract}
Using plastic as additive in pavement has gained popularity for the past several years. Plastics waste is a serious environmental issue due to its non-biodegradable properties and hard to be disposed. There is a high demand of plastics in the industries as a packaging and disposable consumer items due to its inexpensive, lightweight and durable properties. Polyethylene (PE) has been extensively used in packaging, pipes, toys, garbage bags and bottles. The purpose of this study is to evaluate the properties of PE modified bituminous mixture in comparison to conventional bituminous mixture. This study utilized both High Density Polyethylene (HDPE) and Low Density Polyethylene (LDPE) granules in order to achieve optimum benefits. Wearing course samples were prepared using Marshall Mix design method and according to Standard Specification for Road Works as guidelines. Laboratory study was performed on the compacted mixtures to determine the optimum bitumen content (OBC) and evaluate the effect of PE on its properties. The modified mixes show promising results: higher stability and lower optimum bitumen content (OBC) when compared to a conventional mix. The results indicate that the addition of $2 \%$ Polyethylene by weight of aggregate reduce the amount of $\mathrm{OBC}$ by $4.2 \%$. Hence, Polyethylene modified bituminous mixture not only can helps reduce the waste plastics but also results in saving in pavement material costs.
\end{abstract}

Keywords: Modified Bituminous Mixture, Polyethylene, Optimum Bitumen Content, Marshall Mix Design

\section{Introduction}

With increasing number in road traffic, coupled with poor design and lack of maintenance has caused continuous deterioration to the pavement. In consideration to improve pavement performance, the modified bituminous mixture has been introduced. The modification of bituminous mixture can be done by incorporating additives in the mix, therefore change the properties of the bituminous mix. Waste materials such as crumb rubber, polymers, shells and fly ash are commonly used as additives to enhance the bituminous mixture properties. One of the uprising and seems promising to increase the pavement strength and performance is by using plastic waste. [1-4].

Plastics waste is a serious environmental issue. There is a high demand of plastics in the industries as a packaging and disposable consumer items due to its inexpensive, lightweight and durable properties [5]. Polyethylene (PE) has been extensively used in packaging, pipes, toys, garbage bags and bottles. Since plastics waste is a non-biodegradable material and hard to be disposed, other means such as recycling or turning it into a useful material is the alternative solutions. PE has good chemical, fatigue and wearing resistance, where the crystallinity of PE increases strength, stiffness and stability [6]. There are three types of PE namely Low Density Polyethylene (LDPE), High Density Polyethylene (HDPE) and Ultra High Molecular Weight Polyethylene (UHMWPE). LDPE and HDPE are widely used in industrial for packaging food and beverages. Previous studies have utilized LDPE and HDPE as additives in bituminous mix [6-8]. 
Bituminous mixture consist of aggregates, bitumen as binder, and filler, mix together normally at high temperature. Additives such as polyethylene can be incorporated into bituminous mixture by two different processes, dry and wet process. The PE, with melting point of $115-135^{\circ} \mathrm{C}$ will be added to the heated aggregate before adding bitumen in dry process. Meanwhile, wet process change the properties of bitumen by blending PE with the bitumen prior to mixing with aggregate. Most of previous studies adopted wet process to analyse the performance of PE in bitumen [9-13]. However, there is an issue where the blending process was not fully dissolve which lead to the separation process occurred and resulted to uneven layer after the additives was added [6]. In addition, wet process limits the usage of plastic waste. [6] suggested that a PE content of $3 \%$ by weight of bitumen is the optimum value, which can improve the rutting resistance while within workability limit. A content of $6 \%$ or higher was not workable due to the high viscosity of the bitumen. Furthermore, [10] found that highest fracture toughness was obtained at mixtures modified with $4.5 \%$ LDPE by total weight of bitumen. In addition, [15] studied on waste plastic in construction of bituminous road stated that the bleeding surface pavements reduce in hot climate and the optimum content to be used is between $5 \%$ to $10 \%$.

Hence, to maximize the usage of PE, this study adopted Marshall Mix design method, and using dry process to prepare the bituminous mixture. By adding the PE to the aggregate, it gives coating to the aggregates surface and helps fill the pores, thus reduce the water absorption. The coatings of waste plastics on the aggregates improves the quality of aggregates which resulted to better binding, increased strength, improve load carrying capability and gave better surface condition [7, 16]. Studies have shown that by adding plastic or PE to the aggregates reduce the aggregate loss by impact and abrasion force, increase specific gravity and show no sign of weathering after subjected to soundness test $[8,16]$ recommended $12 \%$ of $\mathrm{PE}$ by the weight of bitumen content and found that the addition of PE increase the stability, reduce the density and slightly increase the air voids and the voids of mineral aggregate in bituminous mixture.

The purpose of this study is to evaluate the properties of bituminous mixture modified with polyethylene. PE used in this study is from waste plastic scraps that has been granulated to form into granules. Two types of PE: low density polyethylene (LDPE) and high density polyethylene (HDPE) were blend at equal proportion and incorporated into bituminous mix by weight of aggregate. Since aggregate constitute up to $95 \%$ of bituminous mixture, this study able to utilize higher PE content. HDPE is stronger but rigid, while LDPE more flexible. Since HDPE and LDPE have their own characteristics and advantages, and lack of research on combination both of the materials, this study utilized both HDPE and LDPE in variation of $1.0 \%, 1.5 \%$ and $2.0 \%$ by total weight of aggregate. In order to evaluate the effects of PE addition on bituminous mixture, the properties of PE modified bituminous mixture were compared to conventional mix and JKR specifications.

\section{Method}

This study was carried out to answer three (3) research questions: (1) What is the effect of HDPE-LDPE blend on Marshall properties of bituminous mixture? (2) What is the optimum percentage of HDPE-LDPE blend can be incorporated into bituminous mixture?, and (3) Is the addition of HDPE-LDPE blend can reduce optimum bitumen content?

In order to answer these research questions, this study consist on laboratory works divided into three phases. The first phase, the materials involved, namely aggregate and bitumen were prepared and tested. Sieve analysis, specific gravity and water absorption, Los Angeles abrasion and aggregate impact test were performed on the aggregate. As for bitumen, softening point test and penetration test were performed. The physical properties of aggregate and bitumen are important since they affect the performance of bituminous mixture. All properties conform to Standard Specification for Road Works (JKR/SPJ/S4-2008). Second phase includes a preparation of laboratory specimens for bituminous mixture of wearing course. In this phase, the properties of control $(0 \% \mathrm{PE})$ and modified mixes $(1 \%, 1.5 \%$ and $2 \% \mathrm{PE})$ were obtained and analysed. From the analysis, OBC for each mix can be determined. In the last phase, three samples at optimum bitumen content for each mix were prepared and tested for bulk specific gravity, stability and flow. The Marshall properties were evaluated and compared with control mix and JKR specification. Detailed explanation followed in the next subsection.

\section{Materials}

The materials used in this study were aggregate, bitumen, mineral filler and HDPE-LDPE blend. Crushed granite (coarse and fine) were supplied by Kuad Quarry Sdn. Bhd. Bitumen of $80 / 100$ penetration grade was used, a common grade for pavement materials in Malaysia. The properties of bitumen are given in Table 1 . The filler used was Ordinary Portland Cement (OPC). Two waste materials used as additive, were Low Density Polyethylene (LDPE) and High Density Polyethylene (HDPE) obtained from Lim Seng Plastic, Ipoh. Both were in granular shape and were mix together at a balance proportion to form HDPE-LDPE blend.

Table 1. Properties of bitumen.

\begin{tabular}{ll}
\hline Test & Test result \\
\hline Specific Gravity & 1.02 \\
Softening Point & 48 \\
Penetration & 84 \\
Penetration Index & 0 \\
\hline
\end{tabular}

\section{Marshall Mix Design Method}

Wearing course samples were prepared using Marshall mix design method and according to Standard Specification for Road Works (JKR/SPJ/S4-2008) as guidelines. Marshall properties such as stability and flow able to provide the performance prediction measure of the mix stability, load 
carrying capability and resistance to permanent deformation. In addition, optimum bitumen content can be determined. Bitumen content of 4.0, 4.5, 5.0, 5.5 and $6.0 \%$ were used for asphaltic concrete wearing (ACW 14) to determine the optimum bitumen content (OBC). ACW14 with maximum nominal aggregate size of $14 \mathrm{~mm}$ was designed using AC14 gradation limit where the percentage passing accordance with Arahan Teknik (Jalan) 5/85.

The process used in this study is dry process where HDPE-LDPE blend were mixed with aggregates prior to adding the bitumen to the mixture. Bitumen was preheated in the oven beforehand. Dry process was used to create coated surface to the aggregate. Polyethylene blend were added during aggregate heating process up to $150-180$ Celsius to enable polyethylene melt and create a film to coat the aggregate surface. Total of 15 samples for control sample $(0 \%$ additive) were prepared based on the mix design, where 3 samples for each of bitumen content in order to obtain average value. Another 45 samples were prepared for modified sample where 15 samples for each percentage of polyethylene added (1.0, 1.5 and $2.0 \%$ by weight of aggregate). All samples approximately 1200 grams in weight were compacted with 75 blows on each side.

Laboratory tests were performed on the compacted bituminous samples to evaluate the properties of control and HDPE-LDPE modified bituminous mixtures. Each of compacted samples were subjected to bulk specific gravity determination in accordance with ASTM D 2726. Bulk specific gravity of the compacted bituminous mixtures used to plot bitumen content versus bulk specific gravity graph, and for voids analysis: void filled with bitumen (VFB) and air voids in the compacted mix (VIM). In addition, compacted bituminous samples also were tested for Marshall stability and flow as per ASTM D 1559.

Bitumen content was plotted against stability, flow, bulk specific gravity and volumetric properties. The optimum bitumen content was determined by averaging five bitumen content obtained from the plotted graphs which corresponding (JKR/SPJ/S4-2008):

1. maximum stability,

2. $3 \mathrm{~mm}$ flow,

3. maximum specific gravity,

4. $4.0 \%$ air voids in the compacted mix (VIM), and

$5.75 \%$ air void in the compacted aggregate filled with bitumen graph (VFB).

Following determination of $\mathrm{OBC}$ for control and HDPE-LDPE modified bituminous mixtures, 3 samples at optimum bitumen content for control and each percentage of HDPE-LDPE blend were prepared and tested for stability, flow, and bulk specific gravity.

\section{Findings}

Marshall stability, flow and volumetric properties were obtained for control and HDPE-LDPE modified bituminous mixture. The addition of HDPE-LDPE blends as additives shows increment in the stability of the bituminous mixture.
From Figure 1, the stability values for modified bituminous mixture at bitumen content of 4 to $5 \%$ are significantly higher than control mix. At $5.5 \%$ bitumen content onwards, the stability shows reduction due to higher content of bitumen can results in mix become too soft and unstable. The maximum stability varies on each \% of PE, lower PE content (1.0 and $1.5 \%$ ) only needs $4.5 \%$ of bitumen to achieve maximum stability, whereas maximum stability achieves at bitumen content of $5 \%$ for mix with $2.0 \%$ PE. Control mix on the other hand needs a much higher bitumen content to obtain maximum stability $(5.5 \%)$. This finding shows that the addition of HDPE-LDPE blend improves the stability of pavement which helps to withstand higher traffic loading, without requiring a higher bitumen content.

Figure 2 shows the flow values for each bitumen content for control and modified bituminous mixes. It shows that the flow increase as the PE content increase. The flow values for $2 \%$ of $\mathrm{PE}$ content added are generally higher than others. At bitumen content of $5 \%$ onwards, the flow values for modified mixes increased with the increase percentage of $\mathrm{PE}$ added. Maximum bulk specific gravity for control and modified bituminous mixes are shown in Figure 3. It is found that the modified bituminous mixture with $2 \% \mathrm{PE}$ achieves maximum specific gravity at $5 \%$ bitumen content, whereas other mixes achieve maximum specific gravity at $5.5 \%$ bitumen content. From Figure 4, bitumen content obtained from the plotted graphs which corresponding $4.0 \%$ air voids in the compacted mix (VIM) shows a decrement as the added PE increase. For control mix, the bitumen content which correspond $4 \%$ air voids is $5.45 \%$, whereas mix with $2 \% \mathrm{PE}$ is $5.1 \%$. In general, the plotted graph in Figure 5 shows the VFB percentage of the modified bituminous mixes higher than control bituminous mixture. The bitumen content of $5.5 \%$ correspond $75 \%$ air void in the compacted aggregate filled with bitumen for control mix, $5.3 \%$ bitumen content for $1 \% \mathrm{PE}, 5.2 \%$ bitumen content for $1.5 \% \mathrm{PE}$ and $4.7 \%$ bitumen content for $2 \% \mathrm{PE}$.

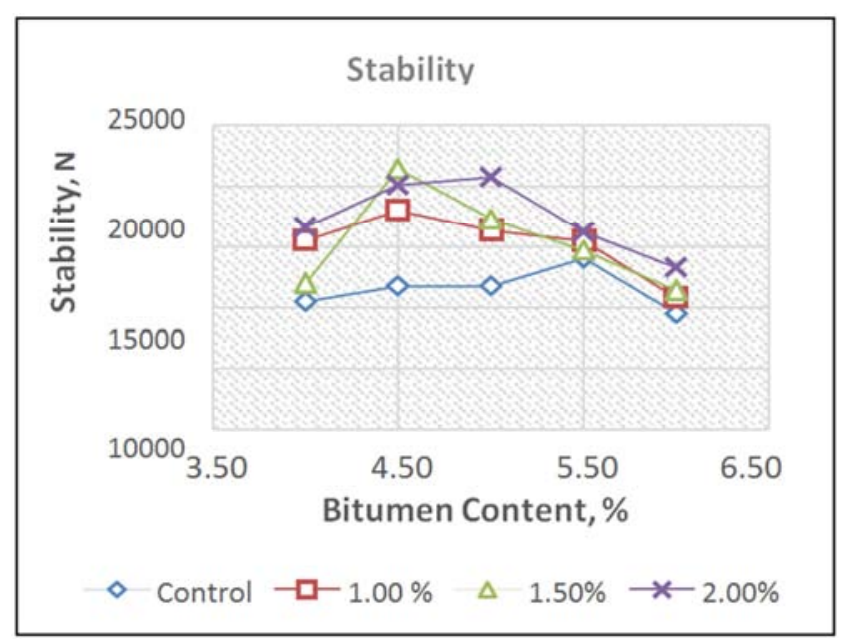

Figure 1. Marshall Stability for each bitumen content with different percentages of $P E$. 


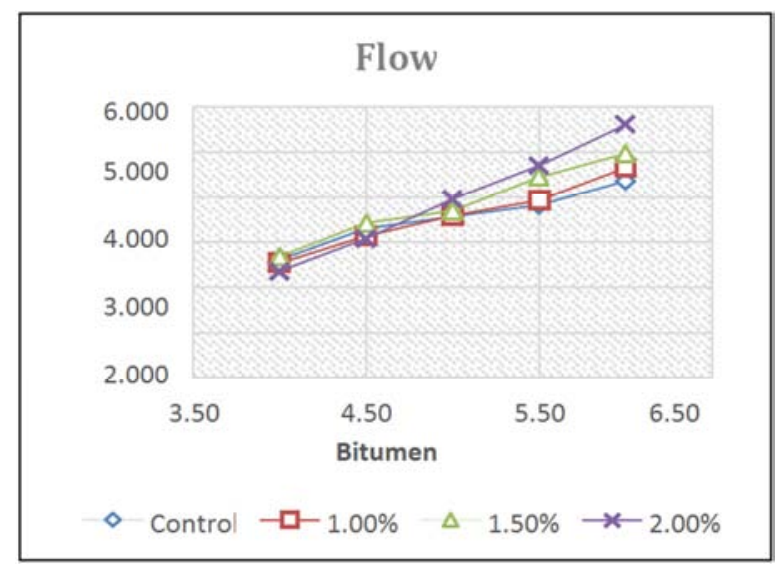

Figure 2. Flow Graph.

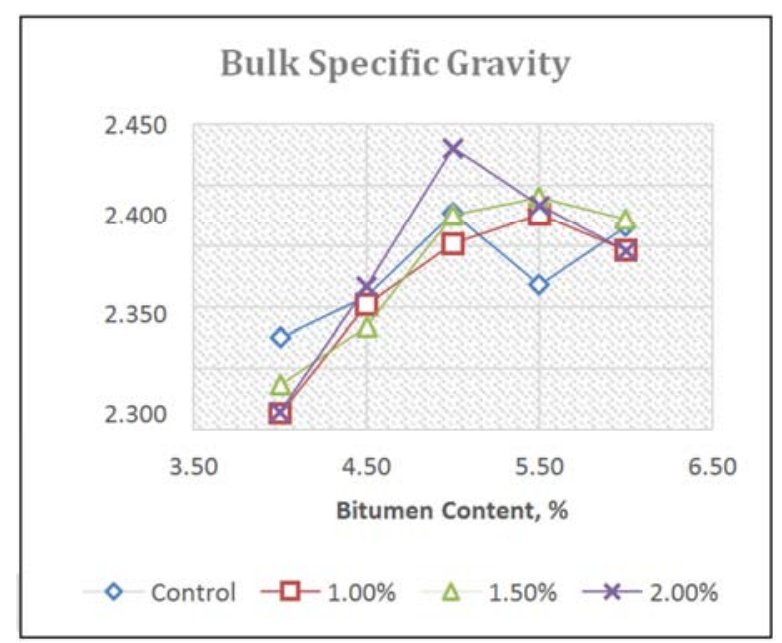

Figure 3. Bulk Specific Gravity Graph.

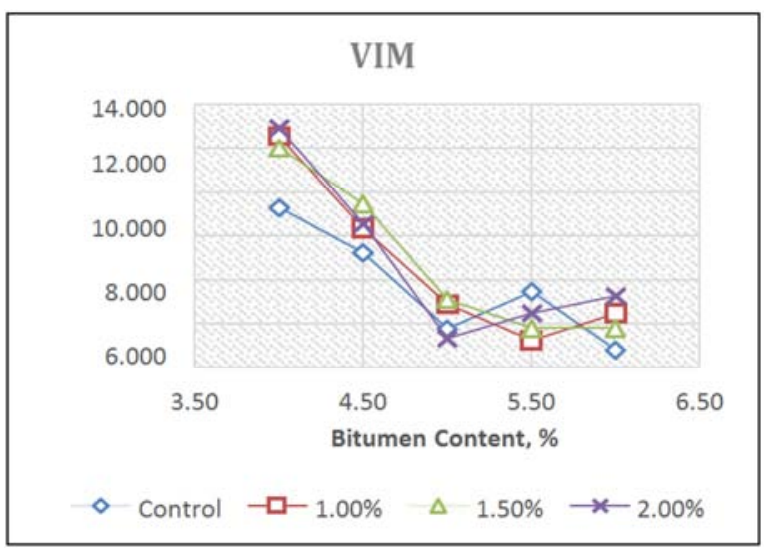

Figure 4. Void in Total Mix Percentage (VIM) Graph.

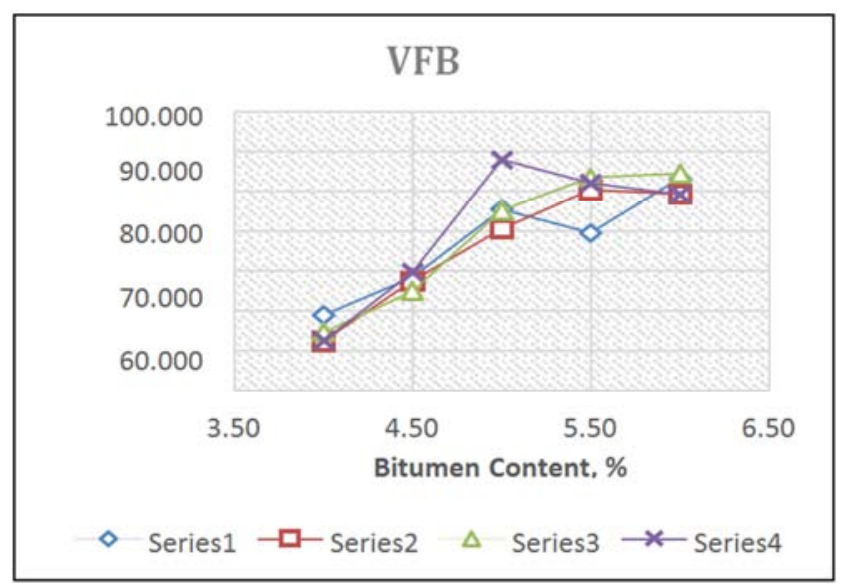

Figure 5. Void in Filled Bitumen Percentage (VFB) Graph.

Based on the plotted graphs, bitumen content which corresponding maximum stability, $3 \mathrm{~mm}$ flow, maximum specific gravity, $4.0 \%$ air voids (VIM), and $75 \%$ VFB were then averaged to obtain $\mathrm{OBC}$. The $\mathrm{OBC}$ values obtained were $5.19,5.04,5.01$ and $4.97 \%$ for control mix, $1.0 \%, 1.5 \%$ and $2 \%$ of HDPE-LDPE blend, respectively. The OBC decreased with the increase percentage of $P E$ added to the bituminous mixes. Therefore, HDPE-LDPE modified mixes require less bitumen.

Three samples at OBC were prepared and tested with the same previous lab work procedure to compare the properties of the samples with standard requirement as stated in Arahan Teknik (Jalan) 5/85. From Table 2, it can be stated that the stability value increase accordance to the value of $\mathrm{PE}$ where $2.0 \%$ of $\mathrm{PE}$ content has the highest value compared to conventional sample. The same trend can be seen in flow value. Flow is the deformation undergone by the sample at the maximum load. Low flow value is not desirable as the mixture may have insufficient bitumen binder, which may lead to durability problems. Meanwhile high flow value indicates the mixture has the potential for permanent deformation. The JKR requirement allowed the flow value between 2 to $4 \mathrm{~mm}$. As can be seen from Table 2, flow value for all PE content higher than control sample and in the range of JKR requirement. From stability and flow value, stiffness of the mix can be determined. Higher stiffness value indicates that the pavement is stiffer which can help to resist permanent deformation. It can be seen that the stiffness properties increased with addition of PE content. However, at 2\% PE content, the stiffness slightly decrease due to the higher flow.

Table 2. Marshall Mix Design Properties for Different Percentage of PE.

\begin{tabular}{llllll}
\hline \multirow{2}{*}{ Quality } & \multirow{2}{*}{ JKR Requirement } & \multicolumn{4}{l}{ HDPE-LDPE content (\%) } \\
\cline { 3 - 6 } & & $\mathbf{0}$ (control) & $\mathbf{1 . 0}$ & $\mathbf{1 . 5}$ & $\mathbf{2 . 0}$ \\
\hline Stability, S (N) & $>8000$ & 12726 & 14941 & 19065 & 21597 \\
Flow, F (mm) & $2.0-4.0$ & 3.3 & 3.5 & 3.6 & 4.0 \\
Stiffness (N/mm) & $>2000$ & 3833 & 4285 & 5352 & 5284 \\
OBC (\%) & $4.0-6.0$ & 5.19 & 5.04 & 5.01 & 4.97 \\
VIM (\%) & $3.0-5.0$ & 4.44 & 4.09 & 3.76 & 3.63 \\
VFB (\%) & $70-80$ & 72.90 & 74.08 & 75.69 & 76.18 \\
\hline
\end{tabular}


JKR requirement allows a value of 3 to $5 \%$ of air voids (VIM). Too high of air voids in the mix can provide path for air and water. On the other hand, low air voids can lead to flushing or bleeding of binder. VIM value decreased when the $\mathrm{PE}$ content increased. In addition, the value of VIM for PE content is lower than control mix. Nevertheless, VIM value for all sample are within the allowable value specified in JKR requirement. For VFB, allowable range based on JKR requirement is between 70 to $80 \%$. The VFB increases with increasing PE content. The allowable range based on the requirement is designed to avoid mixture that is susceptibility to rutting under heavy traffic conditions. If the VFB is too low, there is not enough bitumen to provide durability and to cater traffic loading. The VFB are within the specified range for both control and modified bituminous mixes.

\section{Conclusions}

By adopting dry process, the bituminous mixture is modified by coating aggregate with polyethylene instead of mixing it in bitumen. This in turns allows higher PE content can be incorporated into the mixture, since dry process did not change the properties of bitumen. In wet method, by blending $\mathrm{PE}$ in the bitumen at higher rate will increase the viscosity of the binder and make it unworkable.

From the findings, it can be concluded that:

1. At 2\% HDPE-LDPE blend, the optimum bitumen content required by bituminous mixture is $4.97 \%$ compared to $5.19 \%$ OBC for control mix. The reduction is $4.2 \%$. In large scale, this will reduce the cost of material.

The Marshall stability increased with the addition of PE. This indicates that the PE increases the strength of the mix and improves load carrying capability.

2. Maximum value of PE content can be incorporated in the bituminous mixture not more than $2 \%$ by weight of aggregate. This is support by flow value of $4 \mathrm{~mm}$, is at the maximum allowable limit specified.

In this study, the addition of HDPE-LDPE blend into bituminous mixture improves the quality of compacted wearing course. Therefore, improve the quality of the pavement. In addition to the improvement of the quality of the pavement, this has helped to utilize the waste plastics at a much higher rate. Moreover, the PE is inexpensive materials and readily available. As use of HDPE-LDPE blend helps to reduce quantity of bitumen, this will reduce the cost of pavement materials subsequently.

For future study, there are some of recommendations that can be done. This study blends HDPE and LDPE at balance proportion. Since both PE has their own characteristic, it is recommends to use different proportion than 50:50. Grade of bitumen may give different result for the properties of bituminous mix. It is recommended to conduct a study with $60 / 70$ penetration grade bitumen. This grade of bitumen has been enforced to be used in road surfacing works in Malaysia starting 2017. In addition, this study only utilized ACW14, different mix designation of aggregates such as ACW20 can be tested for future study. It is also recommended to perform further laboratory test such as Rutting, Moisture Induced Damage, Stripping test and Repeated Load Indirect Tensile on the mix.

\section{References}

[1] R. Manju, Sathya S and Sheema K, "Use of Plastic Waste in Bituminous Pavement." International Journal of ChemTech Research. CODEN (USA): IJCRGG, ISSN: 0974-4290, ISSN (Online): 2455-9555. Vol. 10 No. 8, pp 804-811, 2017.

[2] Anzar Hamid Mir, "Use of Plastic Waste in Pavement Construction: An Example of Creative Waste management." IOSR Journal of Engineering (IOSRJEN). ISSN (e): 2250-3021, ISSN (p): 2278-8719 Vol. 05, Issue 02 (February. 2015), ||V1\| PP 57-67.

[3] Brajesh Mishra and Ravi Shankar Mishra, "A Study on Use of Waste Plastic Materials in Flexible Pavements." International Journal of Innovative Research in Science, Engineering and Technology. ISSN (Online): 2319-8753, ISSN (Print): 2347-6710. Vol. 4, Issue 8, August 2015.

[4] Anurag V. Tiwari and Y R M Rao. "Study of Plastic Waste Mixed Bituminous Concrete Using Dry Process for Road Construction." The Asian Review of Civil Engineering. ISSN: 2249 - 6203 Vol. 6 No. 2, 2017, pp. 1-6.

[5] Hopewell, Jefferson, Robert Dvorak, and Edward Kosior. "Plastics recycling: challenges and opportunities." Philosophical Transactions of the Royal Society B: Biological Sciences 364: 1526 (2009): 2115-2126. doi: 10.1098/rstb.2008.0311.

[6] Ghuzlan, Khalid A, Ghazi Al-Khateeb, and Yazeed Qasem. "Rheological Properties of Polyethylene-Modified Asphalt Binder." Paper presented at The 3rd Annual International Conference on Civil Engineering-ATINER, Athens, Greece, June 10-13, 2013.

[7] Khurshid, M Bilal, Sarfaz Ahmed, Muhammad Irfan, and Sajid Mehmood. (2013). "Comparative Analysis of Conventional And Waste Polyethylene Modified Bituminous Mixes." Paper presented at The International Conference on Remote Sensing, Environment and Transportation Engineering (RSETE), Nanjing, China, July 26-28, 2013.

[8] Awwad, Mohammad T. and Lina Shbeeb. "The Use of Polyethylene in Hot Asphalt Mixtures." American Journal of Applied Sciences 4: 6 (2007): 390-396. doi: 10.3844/ajassp.2007.390.396.

[9] Hınıslığlu, Sinan, and Emine Ağar. "Use of waste high density polyethylene as bitumen modifier in asphalt concrete mix." Materials Letters 58: 3-4 (2004): 267-271.

[10] Othman, Ayman M. "Effect of Low-Density Polyethylene on Fracture Toughness of Asphalt Concrete Mixtures." Journal of Materials in Civil Engineering 22: 10 (2010): 951-967.

[11] Punith, V S and A. Veeraragavan. "Behavior of Reclaimed Polyethylene Modified Asphalt Cement for Paving Purposes." Journal of Materials in Civil Engineering 23: 6 (2011): 833-845. doi: 10.1061/(ASCE)MT.1943-5533.0000235. 
[12] Habib, Noor Zainab, Ibrahim Kamaruddin, Madzalan Napiah and Isa Mohd Tan. "Rheological Properties of Polyethylene and Polypropylene Modified Bitumen." International Journal of Civil and Environmental Engineering 3: 2 (2011): 96-100.

[13] Ali, Tariq, Nouman Iqbal, Mehboob Ali, and Khan Shahzada. "Sustainability Assessment of Bitumen with Polyethylene as Polymer." Journal of Mechanical and Civil Engineering 10: 5 (2014): 01-06.

[14] Abd-Allah, Ahmed Mohamady, Mohamed Ibrahim El-sharkawi Attia, Mahmoud Fathy Abd-Elmaksoud Khamis, and Eslam Magdy Mohammed Deef-Allah. "Effect of Using Polymers on Bituminous Mixtures Characteristics in Egypt." Journal of Mechanical and Civil Engineering 11: 4: VII (2014): 54-63.

[15] Vamshi, Avula. "Use of waste plastic in construction of bituminous road." Journal of Engineering 2: 3 (2013): 123-128.

[16] Rajasekaran, S, R Vasudevan, and Samuvel Paulraj. "Reuse of Waste Plastic Coated Aggregates-Bitumen Mix Composite for Road Application - Green Method." American Journal of Engineering Research 2: 11 (2013): 1-13. 